\title{
THREE-DIMENSIONAL ANALYSIS OF NORMAL FAULT ZONES IN KARDIA MINE, PTOLEMAIS BASIN, NW GREECE
}

\author{
Delogkos E. ${ }^{1}$, Manzocchi T. ${ }^{1}$, Childs C. ${ }^{1}$, Sachanidis C. ${ }^{2}$, Barmpas T. ${ }^{2}$, \\ Chatzipetros A. ${ }^{3}$, Walsh J.J. ${ }^{1}$ and Pavlides S. ${ }^{3}$ \\ ${ }^{I}$ Fault Analysis Group, School of Earth Sciences, University College Dublin, Dublin, Ireland, \\ efstratios.delogkos@ucdconnect.ie,tom.manzocchi@ucd.ie,conrad.childs@ucd.ie, \\ john.walsh@ucd.ie \\ ${ }^{2}$ Public Power Corporation of Greece, Western Macedonian Lignite Centre, Ptolemais, Greece, \\ c.sachanidis@dei.com.gr,tr.barmpas@dei.com.gr \\ ${ }^{3}$ Aristotle University of Thessaloniki, School of Geology, Thessaloniki, Greece, \\ pavlides@geo.auth.gr,ac@geo.auth.gr
}

\begin{abstract}
Six normal fault zones, with throws ranging from a few meters up to $50 \mathrm{~m}$, were studied within an active, open pit, lignite mine in Ptolemais. Each fault was mapped 20 times over a period of five years because at intervals of ca. 3 months working faces are taken back between 20 and $50 \mathrm{~m}$ exposing fresh fault outcrops for mapping. Various resolutions of photographs and structural measurements were imported into a fully georeferenced $3 D$ structural interpretation package, resulting in aseismic scale and outcrop resolution $3 D$ fault volume with outcrop and panoramic photographs acting as the seismic sections in equivalent seismic surveys. Low resolution $3 D$ models for the fault system structure at mine scale and higher-resolution $3 D$ models for the fault zone structure were produced after geological interpretation and they can be used for qualitative and quantitative analysis.

Keywords: Normal faults, Fault geometry, 3D structural model, Kardia lignite mine.
\end{abstract}

\section{Пврі́ $\eta \psi \eta$}

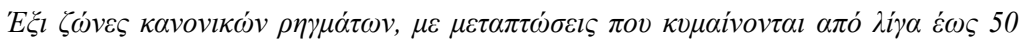

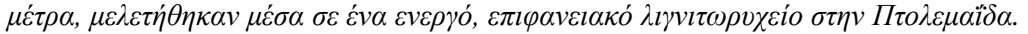

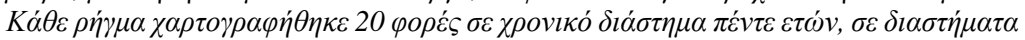

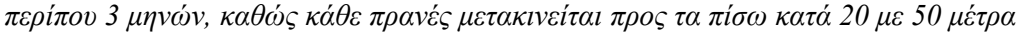

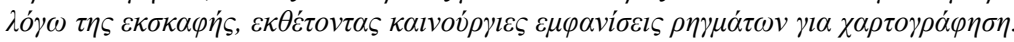

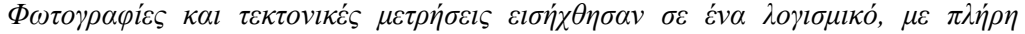

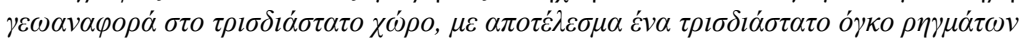

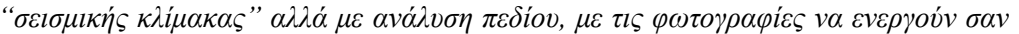

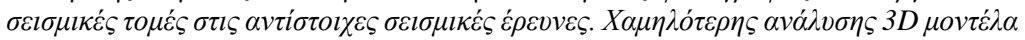

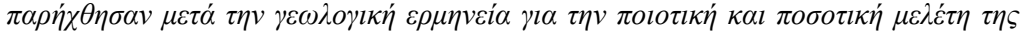

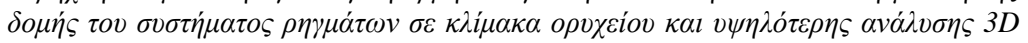

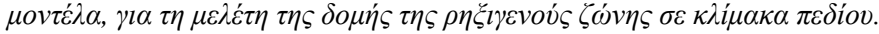

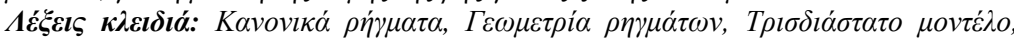

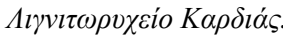




\section{Introduction}

Faults are zones of extreme internal complexity and heterogeneous strain distribution over a wide range of scales. Although this complexity does not lend itself to a simple description to which all faults conform, a simplified and generalised description of faults is required to achieve a better understanding of fault evolution and for many practical applications, such as the production of oil from faulted reservoirs and earthquake hazard assessment (Childs et al., 2009).

A common feature of faults on all scales is the frequent presence of segmented fault arrays containing two or more fault segments which can be hard-linked by discrete faults or soft-linked by zones of continuous deformation (Peacock and Sanderson, 1991; Walsh and Watterson, 1989, 1990, 1991; Childs et al., 1995, 1996; Walsh et al., 2003). Fault linkage is a dynamic process that evolves with increased displacement (Peacock and Sanderson, 1994; Childs et al., 1995; Walsh et al., 1999; Kristensen et al., 2008).

In the published literature many attempts have been made to investigate and understand the fault zone structure and evolution by qualitative and quantitative analysis of various fault components such as thickness, length and displacement. Such data in the published literature are mainly derived from outcrop studies (2D), detailed geological-fault maps (2D), digital elevation models combined with satellite images (2D) and seismic interpretations (3D).

Data derived from outcrop studies are characterized by their high resolution but lack of a threedimensional context, in contrast to seismic data which can be fully $3 \mathrm{D}$ but have very low resolution compared to outcrop data (the best quality seismic data is unable to resolve faults with throws less than $5 \mathrm{~m}$ ).

The goal of this paper is to examine the levels of and controls on geometrical complexity of fault zones by using an exceptional dataset which allows a truly $3 \mathrm{D}$ analysis of the fault zonesat outcrop resolution on a seismic scale. A few similar attempts for 3D investigation of faults at outcrop resolution have been made in the past (Koestler and Reksten, 1995; Childs et al., 1996; Kristensen et al., 2008).

\section{Data and Methodology}

\subsection{Basic Geology and Structure of Kardia Mine}

The dataset used in this study is derived from Kardia mine which is one of the four, active, open pit, lignite fields in Ptolemais Basin, W. Macedonia, Greece(Fig. 1).The Ptolemais Basin is an elongated intramontane lacustrine basin and is part of Florina-Ptolemais-Servia Basin which is a NNW-SSE trending graben system that extends over a distance of $120 \mathrm{~km}$ from Bitola in the Former Yugoslavian Republic of Macedonia (F.Y.R.O.M.) to the village of Servia, south-east of Ptolemais, Greece (Pavlides, 1985). The depression is filled with a 500-600 $\mathrm{m}$ (in a few areas up to about 1000 $\mathrm{m}$ ) thick succession of sediments which are divided into the lower (Upper Miocene to Lower Pliocene) formation, the Pliocene middle formation and the Quaternary upper formation. The Pliocene middle formation contains the upper and lower lignite seams which alternate with clays, marls, sandy marls and sands (Pavlides, 1985; Koufos and Pavlides, 1988).

The basin is bounded by two fault systems which can be related to two extensional episodes (Pavlides and Mountrakis, 1987; Mercier et al., 1989). The first, Late Miocene episode resulted in the origin of the basin in response to NE-SW extension, which was subsequently subjected to NWSE extension during the Quaternary, resulting in the NE-SW-striking faults which currently bound a number of sub-basins, including the basins of Florina, Ptolemais and Servia (Pavlides and Mountrakis, 1987, Fig. 1). 


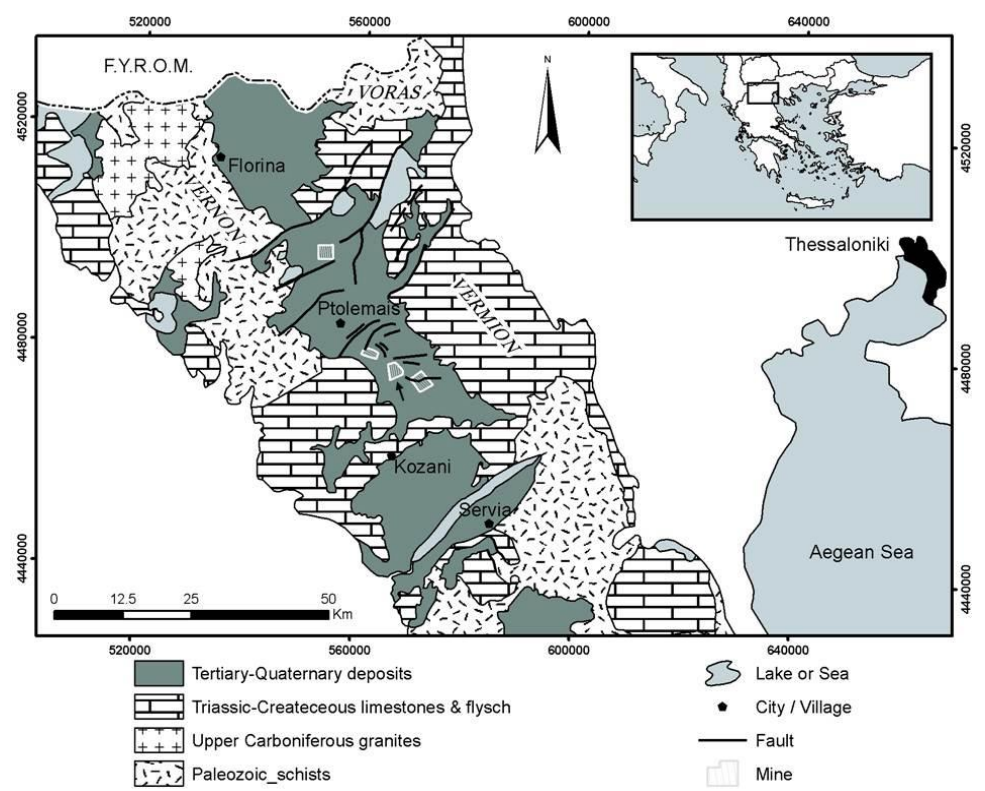

Figure 1 - Simplified geological sketch map of the Florina-Ptolemais-Servia Basin (after Pavlides, 1985; IGME, 1997 and Steenbrink et al., 2000). The black arrow indicates the Kardia lignite field.

Kardia lignite field is situated approximately in the central part of the Neogene lignite basin and is dominated by the later faults which have approximately E-W orientations. In all, six normal fault zones with throws ranging from a few meters up to $50 \mathrm{~m}$ displace the lignite-marl sequence in the mine (Fig.2).

The faults form soft-linked systems (Walsh and Watterson, 1991), characterised by a prevalence of fault tips as opposed to branch-points, with ductile bed rotations between faults accommodating transfers of strain between adjacent faults (Fig.3). Quantitative analysis of the faults indicates that these systems are extremely soft and that for a given throw, these faults are both shorter and more segmented than many other fault systems (Fault Analysis Group, 2011; Delogkos, 2011).

\subsection{Sampling}

As mentioned above, Kardia mine is one of the four active lignite fields in Ptolemais Basin, and every few months fresh fault outcrops are exposed due to the continuous mining operations.

Kardia mine consists of six principal benches and faces which are in average $2.5 \mathrm{~km}$ long. The mine faces, with a height of ca. $20 \mathrm{~m}$, step to the west from the bottom to the top of the mine and are separated by the benches which have a width of ca. $100 \mathrm{~m}$ (Fig. 4). In each bench, a huge excavator undertakes the excavation of lignite and moves each face back by about $30 \mathrm{~m}$ each pass, exhuming fresh outcrop. In addition to the main faces, small faces, with heights up to $4 \mathrm{~m}$, are well exposed in trenches which are created by the excavators in the benches between the main faces (see benches 4 and 5 in Fig. 4). 


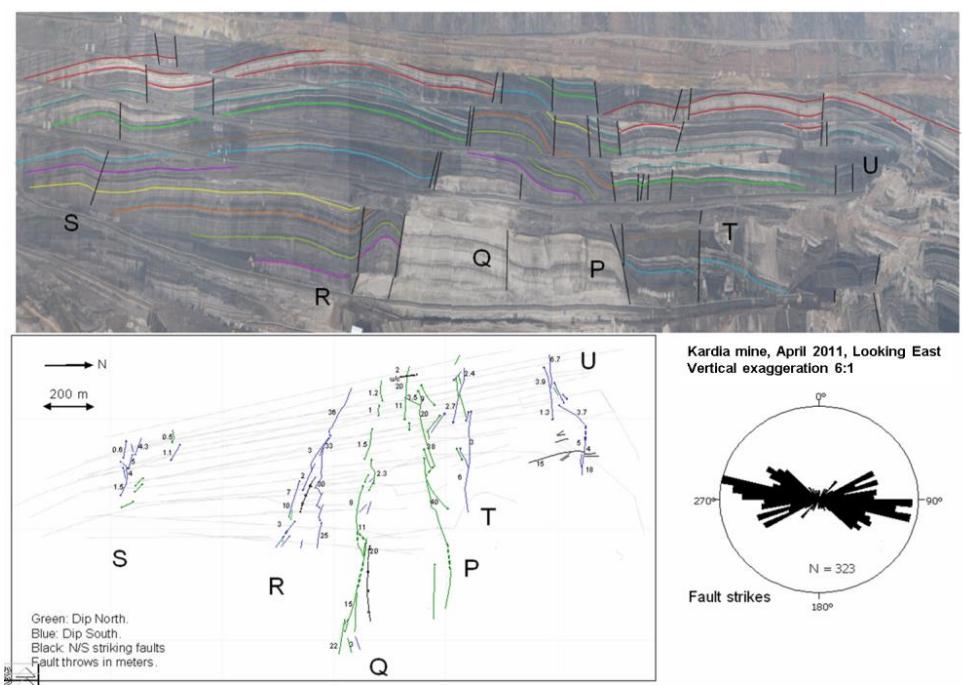

Figure 2 - a) A vertically exaggerated photomontage of the mine showing the faults and some of the horizons, b) a detailed map of the fault zones oriented in sympathy to the photomontage and c) rose diagram summarising the strikes of the normal faults (Fault Analysis Group, 2011).

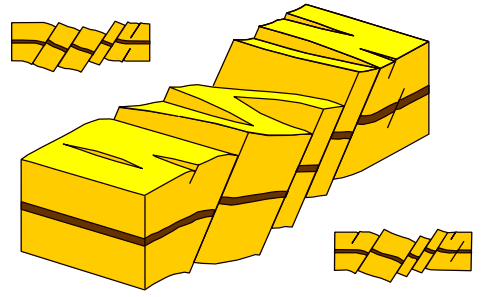

Figure 3 - Cartoon of a soft-linked fault system, characterised by ductile rotation of faults and beds at all stages of deformation (Walsh and Watterson, 1991).

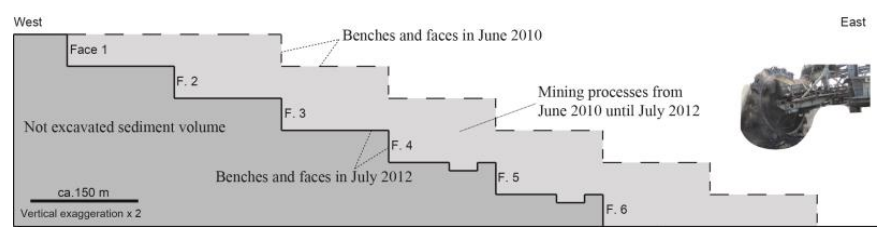

Figure 4 - Cartoon showing a cross-section of Kardia mine. The dashed line shows the faces and the benches as they were in June 2010 and the thick line as they were in July 2012. Light grey colour shows the area that has been excavated from June 2010 to July 2012.

We have visited and mapped the mine 20 times from June 2010 until now, at intervals of ca. 3 months, during which time each face is taken back between 20 and $50 \mathrm{~m}$ and fresh fault outcrops are subsequently available for mapping. The data collected during each fieldwork campaign are various resolutions of photographs, accurate GPS locations, structural measurements and interpretations for all the faults and all the other structures observed in the mine, such as normal or 
reverse drag. In this paper, the area that is covered by our data is from June 2010 until July 2012, 9 field seasons in total, and it is shown by light grey colour in Fig. 4.

Various resolutions of photographs include: a) A set of panoramic photographs of the whole mine which are taken from a distance of ca. $1.5 \mathrm{~km}$ away from the mine faces (Fig. 2.a).b) Outcrop-scale photographs which are taken from a distance of ca. $40 \mathrm{~m}$ from each fault, perpendicular to the face and using a meter-stick at the bottom of the face for scale. c) Very high resolution panoramic photographs for individual faults showing in detail the complexity of the fault zones such as multiple fault slip surfaces and lignite or marl smear.

Structural measurements in the field referred to orientations (strike, dip and dip direction) for all main fault slip surfaces, synthetic and antithetic faults. Detailed measurements of orientations were recorded for observable changes in strike and/or dip along the faults at outcrop-scale; abundant vertical strike refraction is a characteristic of these faults. Changes in bedding due to faulting, such as bed rotations within fault zones, normal and reverse drag, were also recorded.

\subsection{Workflow for inputting data into a fully georeferenced 3D structural interpretation package}

Three-dimensional models of the fault system were produced by placing our data within a fully georeferenced 3D structural interpretation package. For this purpose, TrapTester, a standard oil industry software package for fault analysis is used. This software is designed to input, process and interpret seismic and well data but not photographs of real-world outcrops. Therefore a non-standard import workflow had to be applied.

Given that the XY coordinates for each fault and for the main structures at each individual face in the mine are known, as are the values of absolute altitude at the bottom and top of the mine faces, then the field dataset can be transferred into TrapTester software

Data covering the whole length of each mining face had to be imported into TrapTester, in order to build mine scale 3D structural model. Each one of the mining faces is cropped from the panoramic photographs and then is imported into TrapTester, in a similar way that the $2 \mathrm{D}$ seismic surveys are imported.

In more detail, two main stages must be followed in order to import the cropped pictures, and the higher resolution close-up pictures, into TrapTester. The first stage is to import the 2D navigation lines of a 2D survey, each of which corresponds to a picture, into TrapTester and then the second stage involves definition of the Z-range ("seismic access definition (SIAC)") for each picture.

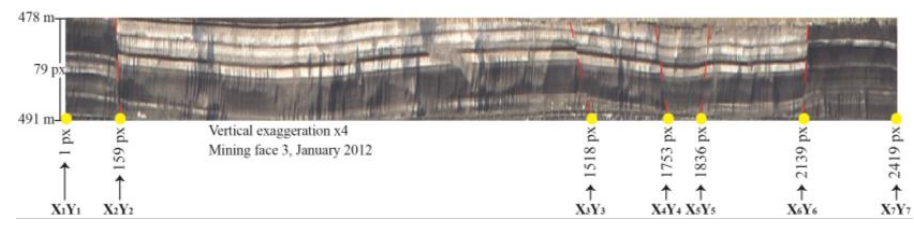

Figure 5 - An example of part of a mine face cropped from a panoramic photograph, showing the data required in order to import it into TrapTester. The XiYi coordinates and the corresponding pixels of the faults and the left and right end of the picture are needed to create the navigation lines. The XiYi coordinates for the left and right end of the picture are not known but they can easily be calculated as the number of pixels per meter is known. The altitude at the bottom of the picture is known and again using the pixels per meter, the altitude at the top can be calculated.

2D navigation lines are in fact the map locations of the cropped pictures, and they are based on the $\mathrm{XY}$ coordinates of the faults, left and right ends of each picture and the corresponding horizontal distances in pixels of each picture (Fig. 5). Concerning the SIAC, each one contains information 
about Z-shift and Z-scaling which are based on location of the top of the picture with respect to the chosen datum (Z-shift) and number of pixels per vertical meter (Z-scaling).

Structural measurements are imported into TrapTester as tri-mesh surfaces which are displayed in 3D space with the dip and dip-azimuth values as they are measured in the field. The information required for loading these data is XYZ locations and orientation of each structural measurement. These tri-mesh surfaces are a very useful guide for optimizing the precision of the structural interpretations. Additionally they are used to illustrate the complexity of the fault zone structures, such as the strike refraction.

Empty sections can be imported into the 2D survey and they can be used for fault and/or horizon interpretations in areas where there are no available outcrop data but the interpretations are very predictable. Including them in the creation and analysis of the 3D fault volume, makes the final results more realistic and accurate. A particular use of empty sections is for placing faults tips located between two consecutive mapped mining faces.

\section{Results}

The result of importing our dataset into the 3D structural interpretation package is a volume similar to a $2 \mathrm{D}$ seismic survey, a data type common in the oil and gas industry. The difference is that our dataset, while at a seismic scale, has outcrop-scale resolution.

This exceptional dataset is used for fault and horizon interpretations. Each fault zone is characterized by about 60 cross-sections perpendicular to ca. $900 \mathrm{~m}$ long and 20 to $80 \mathrm{~m}$ high areas of the fault surface (Figs. 6 and 7).

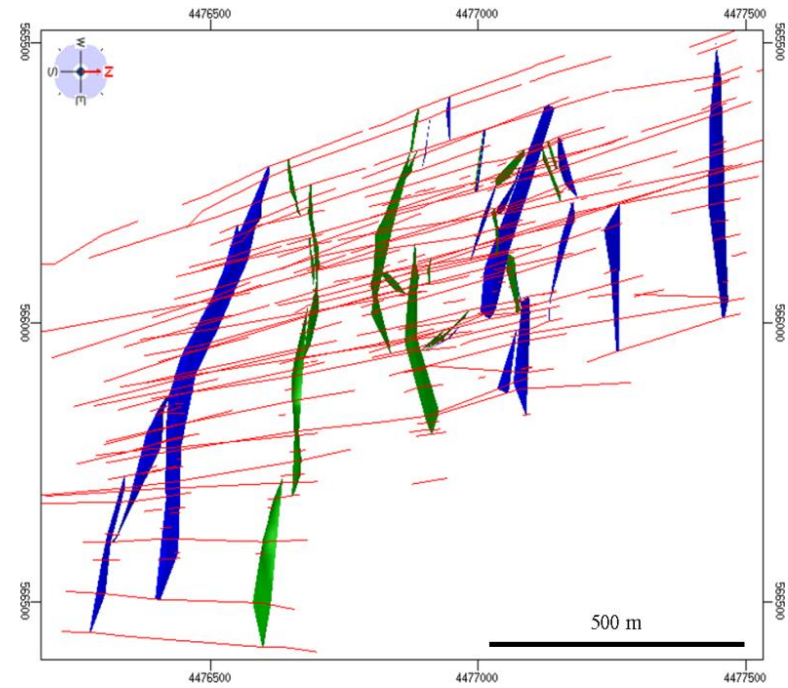

Figure 6 - Map view of the interpreted fault zones from Kardia mine. Interpretations are based on data derived from nine field seasons and cover the area shown by the navigation lines (red lines). South-dipping faults are shown with blue colour and north-dipping faults with green colour.

The layering of lignite and marl makes these sediments ideal for detailed displacement analysis along the faults in cross-section and along strike as individual horizons are continuous across the scale of the structures investigated. 
Various resolutions of fault interpretations and respectively 3D models can be made. We use this dataset to build low resolution 3D models for the fault system structure at mine scale (Fig. 7) and higher-resolution 3D models for the fault zone structure (Fig. 8). The fault zone is a part of a fault system.

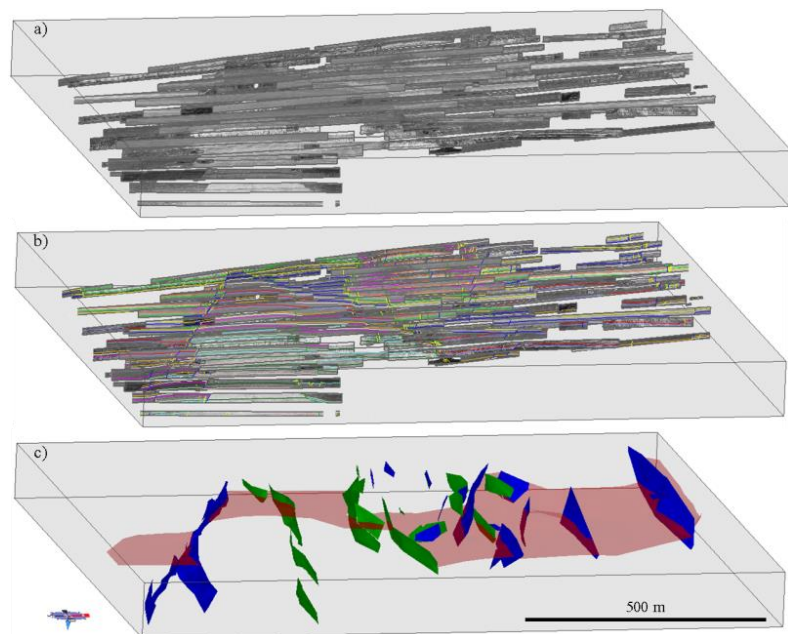

Figure 7 - Lateral view of the 3D TrapTester model showing: a) All the mining faces, which are cropped from the panoramic photographs and are imported into TrapTester like seismic sections. b) As (a) but including fault and horizon interpretations. c) Interpretation of the data showing five fault zones, the majority of which comprise several fault surfaces, which displace the lignite-marl sequence up to $\mathbf{4 0}$ meters. The blue fault surfaces dip to the south, and green fault surfaces dip to the north. The transparent red surface, which is displaced by the faults, is one of the interpreted horizons and is located near the middle of the exposed stratigraphic sequence.
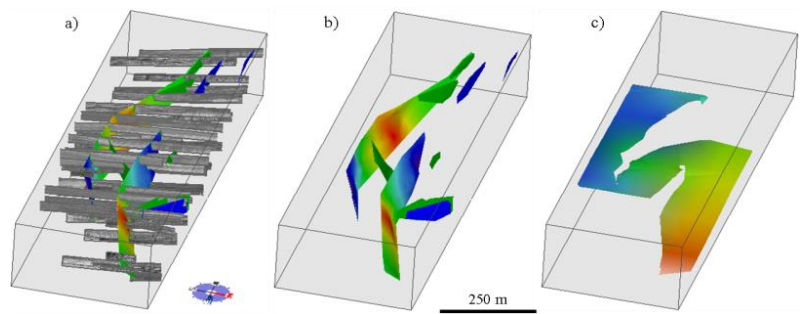

Figure 8 - Lateral view of the 3D TrapTester model showing a fault zone with maximum throw of ca. $36 \mathrm{~m}$. This is actually an almost intact relay zone and consists of two main fault surfaces, a minor breaching fault and some synthetic and antithetic faults. a) All data. b) All the interpreted faults. The variation of the colours on the two main fault surfaces shows the

displacement distribution (red is high displacement). The displacement is transferred

between the relay bounding faults by bed rotation (c) and small offset along the minor breaching fault. c) One of the interpreted horizons showing the bed rotation within the relay zone. The variation of the colours shows the depth (red in deeper).

In order to build the 3D fault system model, minor synthetic and antithetic faults are ignored and only the main faults and the main structure of the lignite-marl sequence which was displaced and 
deformed because of faulting are interpreted. In contrast, for the high resolution 3D fault zone models, all the fault structures are taken into account.

The final 3D fault models can be used for qualitative and quantitative analysis of the fault system and fault zone structure providing insights on the growth, propagation, evolution and geometrical complexity of faults, which will provide a basis for improving conceptual models of fault systems and fault zones, which underpin many practical applications such as the production of oil and gas from faulted reservoirs and earthquake hazard assessment.

\section{Conclusions}

Using this exceptional dataset from the active opencast lignite field in the Ptolemais basin, we construct 3D fault zone models at outcrop resolution on a seismic scale by importing various resolutions of photographs and structural measurements into a fully georeferenced 3D structural interpretation package. These models allow us to investigate and analyse fault zone structure in $3 \mathrm{D}$, andat outcrop resolution, a combination impossible to accomplish using either outcrop or seismic data.

\section{Acknowledgements}

This work was carried out as part of the Earth and Natural Sciences Doctoral Studies Programme, funded by the Higher Education Authority (HEA) through the Programme for Research at Third Level Institutions, Cycle 5 (PRTLI-5), co-funded by the European Regional Development Fund (ERDF). The work was also funded by the multi-company QUAFF project. The authors would like to thank Badley Geoscience Ltd. for the use of TrapTester6 software. The authors also thank the Public Power Corporation ( $\triangle \mathrm{EH} / \Lambda \mathrm{K} \Pi \mathrm{A}$ ) for permission to work in the mines and the corporation's employees for their hospitality and assistance in the field during the last four years. Thanks to the other members of the Fault Analysis Group for the field assistance and useful discussions.

\section{References}

Childs, C., Watterson, J. and Walsh, J.J.,1995. Fault overlap zones within developing normal fault systems, Journal of the Geological Society, London, 152, 535-549.

Childs, C., Watterson, J. and Walsh, J.J., 1996. A model for the structure and development of fault zones, Journal of the Geological Society, 153, 337-340.

Childs, C., Manzocchi, T., Walsh, J.J., Bonson, C.G., Nikol, A. and Schöpfer, M.P.J., 2009. A geometric model of fault zone and fault rock thickness variations, Journal of Structural Geology, 31(2), 117-127.

Delogkos, E., 2011. Quantitative analysis of geometric evolution of fault zones of Mavropigi lignite field in Ptolemais Basin (W. Macedonia, Greece), Master thesis, Aristotle University of Thessaloniki, Greece, 98 pp.

Fault Analysis Group, UCD., 2011. Structural geological observations in the Ptolemais lignite mines - a preliminary report, Unpublished.

Koestler, A.G. and Reksten, K., 1995.Fracture-network 3D characterization in a deformed chalk reservoir analogue - the Lagerdorf case, SPE Formation Evaluation, 10(3), 148-152.

Koufos, G. and Pavlides, S., 1988. Correlation between the continental deposits of the lower Axios valley and Ptolemais basin, Bull Geol. Soc. Greece, 20, 9-19.

Kristensen, M.B., Childs, C.J. and Korstgerd, J.A., 2008. The 3D geometry of small-scale relay zones between normal faults in soft sediments, Journal of Structural Geology, 30, 257-272.

Mercier, J.L., Sorel, D. and Vergely, P., 1989. Extensional tectonic regimes in the Aegean basins during the Cenozoic, Basin Res., 2, 49-71.

Pavlides, S., 1985. Neotectonic evolution of the Florina-Vegoritis-Ptolemais basins, PhD thesis, University of Thessaloniki Greece, $256 \mathrm{pp}$. 
Pavlides, S.B. and Mountrakis, D.M., 1987. Extensional tectonics of northwestern Macedonia, Greece, since the late Miocene, J. Struct. Geol., 9(4), 385-392.

Peacock, D.C.P. and Sanderson, D.J., 1991. Displacement and segment linkage and relay ramps in normal fault zones, Journal of Structural Geology, 13, 721-733.

Peacock, D.C.P. and Sanderson, D.J., 1994. Geometry and development of relay ramps in normal fault systems, American Association of Petroleum Geologists Bulletin, 78, 147-165.

Steenbrink, J., Van Vugt, N., Kloosterboer-van Hoeve, M.L. and Hilgen, F.J.,2000. Refinement of the Messinian APTS from sedimentary cycle patterns in the lacustrine Lava section (Servia Basin, NW Greece), Earth Planet. Sci. Lett., 181(3-4), 161-173.

Walsh, J.J. and Watterson, J., 1989. Displacement gradients on fault surfaces, Journal of Structural Geology, 11, 307-316.

Walsh, J.J. and Watterson, J., 1990. New methods of fault projection for coalmine planning, Proc. Yorks. Geol. Soc., 48, 209-219.

Walsh, J.J. and Watterson, J., 1991. Geometric and kinematic coherence and scale effects in normal fault systems. In: Geometry of Normal Faults, Roberts, A., Yielding, G. and Freeman, B., eds., Spec. Pubis Geol. Soc. Lond., 56, 193-203.

Walsh, J.J., Watterson, J., Bailey, W. and Childs, C., 1999. Fault relays, bends and branch-lines, Journal of Structural Geology, 21, 1019-1026.

Walsh, J.J., Bailey, W.R., Childs, C., Nicol, A. and Bonson, C.G., 2003. Formation of segmented normal faults: a 3-D perspective, Journal of Structural Geology, 25, 1251-1262. 